\title{
Follow-up of kidney donors at a single Center in South Africa
}

\author{
Naicker S, Azor M, Sukool A, Holmes I, Muranda A and Haffejee A A \\ Renal Unit, Addington Hospital and Departments of Medicine and Surgery, University of Natal Medical School, \\ Durban, South Africa
}

\begin{abstract}
:
\section{Background}

There is a worldwide shortage of organ donors. In our province, KwaZulu / Natal, this problem is more pronounced as the rate of cadaveric donation is very low. Thus both patients and nephrology staff are under pressure to seek living donors.
\end{abstract}

\section{Methods and results}

We studied 135 living kidney donors in ten years period: 85 females and 50 males; $78(57.8 \%)$ were of Indian origin, $33(24.4 \%)$ Black, $15(11.1 \%)$ White and $9(6.7 \%)$ of mixed race groups. The majority of donors $(57 \%)$ were siblings, while $14.8 \%$ were parents, $6.7 \%$ children, $17.8 \%$ spouses and $3.7 \%$ were cousins. The mcan age of donors was 34.2 years (range 21-56 years). Donors were hospitalised for a mean peroid of 6.1 days (range 3-15). Post-operative complications were left lobe atelectasis and chest infection in $11.1 \%$, other infections in $5.2 \%$, pneumothorax in $2.2 \%$, ileus in two cases, depression in one and prolonged pain at the site of surgery in $11.1 \%$. Proteinuria was noted in three cases $(0.26$ $\mathrm{gm} / \mathrm{d}$ and $0.66 \mathrm{gm} / \mathrm{d}$ in two donors at 2 years and 0.27 $\mathrm{gm} / \mathrm{d}$ in the third case at 10 years).

Blood pressure levels were virtually unchanged from pre-nephrectomy data.

\section{Conclusion}

This study confirms that unilateral nephrectomy in normal individuals is associated with few major

Correspondence and offprint requests to: Naicker S, Renal Unit, Block SS, Addington Hospital, P 0 Box 977, Durban 4000, South Africa. adverse effects and living donors in renal transplantation is a viable option.

Key words: follow-up; kidney donors; uni-nephrectomy

\section{Introduction}

The shortage of cadaveric donors with increasing patients on dialysis population is a world-wide problem. This has encouraged the use of living kidney donors especially in view of the reported negligible morbidity and mortality in addition to improved graft survival.

There is a marked shortage of cadaveric donors in South Africa (Table 1) and more so in our province of KwaZulu / Natal (Table 2). Therefore the transplantation teem at our centre has to seek living donors.

Table 1. Renal transplantation in South Africa (1994)

\begin{tabular}{|c|c|}
\hline Number of transplant Centers & 8 \\
\hline Number of functioning transplants & 1578 \\
\hline Number of transplants in 1994 & 299 \\
\hline cadaver & 253 \\
\hline living donors & 46 \\
\hline Transplant rate & $8.7 \mathrm{pmp}$ \\
\hline
\end{tabular}

Table 2. Renal transplantation in Zulu/Natal (1987-1996)

$\begin{array}{lc}\text { Related donors } & 107(44.4 \%) \\ \text { Living unrelated donors } & 27(11.6 \%) \\ \text { Cadaveric donors } & 106(44 \%) \\ \text { Total } & 240\end{array}$


Our renal transplant unit at Addington Hospital, Durban is the only facility serving the public sector in the province of Kwa Zulu / Natal. Both our Center and a private transplant unit serve a population of approximately 7 million.

\section{Materials and methods}

One hundred and thirty five adult living kidney donors in a ten year period from 1987-1996 were reviewed. The initial assessment of these potential donors included $\mathrm{ABO}$ and HLA typing, $\mathrm{B} \& \mathrm{~T}$ lymphocyte matching with their recipients. Detailed assessment was done by a physician, psychologist and social worker.

Laboratory and radiological investigations included: Complete blood picture, chemistry, urine analysis, urine culture and creatinine clearance, measurement of $24 \mathrm{~h}$. urine protein, Tc $99 \mathrm{~m}$ DTPA GFR, chest radiography, pyelogram and renal angiography. Left nephrectomy was preferred because of the longer length of the left renal vein. Multiple arterial supply to the left kidney was missed on angiography in 10\% of donors and was not a contra-indication to harvesting the left kidney and up to three renal vessels were accepted for transplantation. In-dwelling urethral catheter was removed after 24 hours and the donors were then mobilised.

Twenty one donors required intra-operative blood transfusion, ranging from 1 to 6 units of packed red cells with a mean of 2 units. Post-operatively annual evaluation of donors was done including blood pressure level and renal function.

\section{Results}

The evaluation of donors was stringent with $37 \%$ of potential donors were accepted as kidney donors at our centre [1].

The majority (57.8\%) of donors were of Indian origin and $85(63 \%)$ were female (Table 3 ). The mean age was 34.2 years.

Table 3. Donor profile

\begin{tabular}{llc}
\hline & & \\
Sex & 85 female, 50 male & \\
Age & 34.2 years (range 21-56 years) & \\
Race & indian & $78(57.8 \%)$ \\
& black & $33(24.4 \%)$ \\
& white & $15(11.1 \%)$ \\
& "mixed" & $9(6.7 \%)$ \\
\hline
\end{tabular}

Seventy seven (57\%) were sibling donors. 20 (14.8\%) of donors were parents, $9(6.7 \%)$ donated to their parents (Table 4); 24 were spouses donors and 5 were cousins.
Table 4. Donor-recipient relationship

\begin{tabular}{lll}
\hline Sibling & female & $77(57 \%)$ \\
& male & 45 \\
& & 32 \\
Parent to child & fermale & $20(14.8 \%)$ \\
& male & 14 \\
Child to parent & & $9(6.7 \%)$ \\
Spouses & & $24(17.8 \%)$ \\
& wives & 20 \\
Cousins & husbands & 4 \\
& & $5(3.7 \%)$ \\
\hline
\end{tabular}

The mean duration of hospitalisation of donors was 6.1 days with a range of 3-15 days. Uncomplicated donor nephrectomies resulted in a mean hospital stay of $5.1 \pm 1.2$ day compared to $6.9 \pm 2.7$ day $(\mathrm{p}=$ 0.0002 ; unpaired t-test). Twenty two donors (16.3\%) suffered infective complications post-operatively, primarily chest infection in smokers (11.1\%); 15 (11.1\%) developed surgical complications: 3 donors had pneumothorax, requiring a chest drain; 2 developed post-operative ileus which resolved after 48 hours of intravenous fluids. Prolonged pain at the site of the nephrectomy scar persisted for several months (range 2-12) in 10 donors, requiring prolonged analgesia and psychological support.

One donor became acutely depressed in the immediate post-operative period. There was no postoperative mortality and no donors required intensive care. All donors returned to their full employment post-operatively.

Table 5. Post-operative complications

\begin{tabular}{llrr}
\hline & & $N$ & $\%$ \\
\hline \multirow{2}{*}{ Infection } & & 22 & 16.3 \\
& - chest infection & 15 & 11.1 \\
& - mild wound sepsis & 3 & 2.2 \\
Surgical & - lower urinary tract infection & 4 & 2.9 \\
& & 15 & 11.1 \\
& - ileus & 2 & 1.5 \\
Acute & - pncumothorax & 3 & 2.2 \\
depression & - prolonged pain & 10 & 7.4 \\
& & 1 & 0.7 \\
\hline
\end{tabular}

One hundred and two donors were attending followup clinic for 1-10 years while 20 have a follow-up period of less than one year and 13 have been lost as the majority of these were from other provinces or countries. The mean rise in serum creatinine was $33.4 \%$ in the follow-up period and was within the normal laboratory reference range.

The mean systolic blood pressure was $118.7 \mathrm{mmHg}$ pre-operatively and $119.1 \mathrm{mmHg}$ at follow-up $(\mathrm{p}=0.76)$ while the mean diastolic blood pressure was 
$74.6 \mathrm{mmHg}$ pre-operatively and $71.8 \mathrm{mmHg}$ at follow-up ( $p=0.01$; students paired t-test); this blood pressure may be a reflection of donors age (mean age of 34.2 years).

Proteinuria ranging from 0.19 to 0.66 grams was found in 3 donors: donor $\mathrm{AH}$ was noted to have proteinuria of 0.26 grams and creatinine clearance of $76 \mathrm{ml} / \mathrm{min}$ at 2 years and 0.19 grams and $145 \mathrm{ml} / \mathrm{min}$ at 5 years; donor $\mathrm{MH}$ developed proteinuria of 0.66 grams at 2 years during pregnancy which resolved completely following delivery; donor SN was noted to have a pre-nephrectomy urine protein excretion of 0.06 grams, which increased to 0.2 grams at 7 years and 0.27 grams at 10 years and was associated with a creatinine clearance of $134-167 \mathrm{ml} / \mathrm{min}$ compared to a post nephrectomy baseline of $87 \mathrm{ml} / \mathrm{min}$. These donors require careful long-term follow-up and assessment.

One donor sustained an inferior myocardial infarct 5 years after donation with full recovery. Two donors died of cancer after 6 years and 10 years of followup.

\section{Discussion}

Currently in renal transplantation living-related donation is most successful. Cadaveric kidneys are inadequate to meet the increasing demands, thus it became mandatory to search for other sources as living unrelated donors or non-heart beating donors. Shorl-term studies have shown that glomerular filtration rate and renal blood flow increase by 40 to $60 \%$ within a few weeks of nephrectomy (2-4). These changes are not accompanied by proteinuria or hypertension [5]. Renal hyperfiltration and hypertrophy are not associated with adverse effects over 10 to 20 ycars of follow-up (6-9). Albuminuria was reported in $7.8 \%$ and microalbuminuria in $36.6 \%$ of donors in Brazil 1 to 14 years after nephrcctomy [10]. The prevalence of hypertension at $19.2 \%$ was similar to that of the general population.

Najarian et al [11], showed in their study 21-29 years after kidney donation, that the frequency of hypertension in the donors was $32 \%$, similar to that in the general population, and the incidence of proteinuria was $23 \%$, comparable to $22 \%$ in their siblings. They also estimated a peri-operative donor mortality of $0.03 \%$ in the USA. Moreover, higher prevalence of hypertension or renal failure was not found 45 years after uni-nephrcctomy in subjects who lost a kidney due to trauma in the second World War [12].

Eighty five percent of kidney donors were alive after 20 years of follow-up in Sweden [13], whereas the expected survival rate was $66 \%$. The causes of death were chiefly due to cardiovascular disease and cancer; there was no death due to renal disease. Hypertension was present in $35 \%$ of donors in this study; $20 \%$ had serum creatinine exceeding 120 umol/l and the average GFR was $48 \mathrm{ml} / \mathrm{min} / 1.73$ M2 (these subjects were all aged 75 years or older).

Our study supports current literature data that unilateral nephrectomy in normal individuals is associated with few major adverse effects and living kidney donation is a viable option. Longitudinal follow-up of kidney donors for $30-40$ years is required to be absolutely certain of the long term safety of kidney donation as suggested by Provost and Brenner [14].

\section{References}

1. Azor M, Holmes I and Naicker S: Reasons for unsuccessful kidney donation. Abstracts, V Congress of African Association of Nephrology. Durban September 1997.

2. Krohn AG, Ogden DA and Holmes JH: Renal function in 29 healthy adults before and after nephrectomy. JAMA 1966; 196: $110-112$.

3. Ogden DA: Donor and recipient function 2-4 years after renal homotransplantation. Ann Intern Med 1967; 67: 998-1006.

4. Pabico RC. McKenna BA and Freeman RB: Renal function before and after unilateral nephrectomy in renal donors. Kidney Int 1975; 8: 166-175.

5. Bertolatus JA, Friedlander MA, S. Scheidt C and Hunsicker LG: Urinary albumen excretion after donor nephrectomy. Am J Kidney Dis 1985; 5: 165-169.

6. Vincenti F, Amend WJC and Kaysen G el al : Longterm renal function in kidney donors. Transplantation 1983; 36: 626-629.

7. Hakim RM, Goldszer RC and Brenner BM: Hypertension and proteinuria Long term sequelae of uninephrectomy in humans. Kidney Int 1984; 25 930-936.

8. Williams SL, Oler J and Jorkasky DK: Long term renal function in kidney donors: A comparison of donors and their siblings. Ann Intern Med 1986; 105: 1-8.

9. Schmitz A, Christensen CK, Christensen $T$ and Solling $K$ : No microalbuminuria or other adverse effects of long-standing hyperfiltration in humans with one kidney. Am J Kidney Dis 1989; 13:131-136.

10. D'Almeida, Keital E and Bittar A, et al: Longterm evaluation of kidney donors. Transplant Proc 1996; 28: 93-94.

11. Najarian JS, Chavers BM, McHugh LE and Matas AJ: 20 years or more of follow-up of living kidney donors. Lancet 1992; 340: 807-810

12. Narkun-Burgess DM, Nolan CR and Norman JE et al : Fortyfive years follow-up after uninephrectomy. Kidney Int 1993; 43: $1110-1115$.

13. Fehnnan-Ekholm I, Elinder CG, Stenbeek M, Tyden G and Groth CG: Kidney donors live longer. Transplantation 1997; $64(7): 976-978$.

14. Provosi AP and Brenner BM: Long-term follow-up of humans with single kidneys the need for longitudinal studies to assess true changes in renal function. Current Opinion Nephrol Hypertens $1993 ; 2521-526$.

\section{Acknowledgements}

We wish to thank Mrs E Shepherd for secretarial assistance. 